\title{
An Alternative Look at Insect Hormones ${ }^{1}$
}

\begin{abstract}
Karel Sláma²
Abstract: The theories of insect hormone action were created some 50-years ago by professional insect endocrinologists. Unfortunately, the scientists slowly passed out and their original results are almost inaccessible. I am one of a few old-fashioned endocrinologists who has survived. The modern topics and priorities are mostly concerned with the isolation of receptors, enzymes (e.g. esterase) and genes (e.g. Met) in the peripheral target tissues. By contrast, the most important hormones of the central neuroendocrine system (i.e. neuropeptides of the neurosecretory cells of the brain, corpora cardiaca, corpora allata) are usually neglected. I found, for example, that ecdysone and ecdysteroids, which were accidentally discovered in the search for an insect moulting hormone, are not true insect hormones. Moreover, the sesquiterpenoid JH-I, which is still believed to be the true juvenile hormone $(\mathrm{JH})$, is also not an insect hormone. Indeed, JH-I turns out to be just one of 4000 juvenoid bioanalogues, mimicking the $\mathrm{JH}$ action. The $\mathrm{JH}-\mathrm{I}$ is a trivial excretory product of exocrine, not endocrine, colleterial glands of the male Cecropia, Hyalophora cecropia (Linnaeus, 1758) silkworms. This paper describes briefly some neglected physiological problems of insect hormone action with the aim to encourage discussions about their interpretations.
\end{abstract}

Key Words: Juvenile hormone, ecdysteroidal vitamin $\mathrm{D}_{6}$, corpus allatum hormone, activation hormone, neurosecretory cells, neuropeptides

The history of insect hormones begins by the discovery of insect brain hormone by Stefan Kopeć in 1917. The next important milestone in the history of insect hormones was the elucidation of the inhibitory role of juvenile hormone $(\mathrm{JH})$ in insect metamorphosis by Sir Vincent B. Wigglesworth in 1936. Another important step was the discovery of JH activity in the lipid extracts of adult male Cecropia, Hyalophora cecropia (Linnaeus, 1758) (Lepidoptera: Saturniidae) silkworms by Carroll M. Williams in 1957, followed by the isolation of the first chemical compound with $\mathrm{JH}$ activity from the excrements of the beetle Tenebrio molitor Linnaeus, 1758 (Coleoptera: Tenebrionidae) by Peter Schmialek in 1961. The active compound appeared to be a trivial sesquiterpenoid alcohol farnesol, which attracted the attention of JH research to isoprenoid chemistry. In 1965, C. M. Williams and Karel Sláma unexpectedly uncovered a "paper factor" with JH activity, which was later identified as an alicyclic isoprenoid compound, juvabione from the wood of the Canadian balsam fir, Abies balsamea (L.) Mill. At the same time, Herbert Röller and his co-workers identified the $\mathrm{JH}$-active principle from the Cecropia extracts as an ester of a sesquiterpenoid acid, 10,11- epoxy-7-ethyl, 3,11-di methyltrideca-2,6,dienoic (homofarnesoic) acid, which became generally known as JH-I, believed to be the true JH of insects (for a review and references, see Sláma 2013).

\footnotetext{
${ }^{1}$ Submitted on September 8, 2015. Accepted on September 19, 2015. Last revisions received on October 24, 2015.

${ }^{2}$ Institute of Entomology, Czech Academy of Sciences, Drnovská 507, 16000 Praha 6, Czech Republic. E-mail: slama@entu.cas.cz
}

DOI: 10.9784/LEB3(3)Slama.01

Electronically available on October 31, 2015. Mailed on October 27, 2015. 
The physiological role of $\mathrm{JH}$ in insect development, metamorphosis and reproduction was first elucidated by Sir V. B. Wigglesworth in 1940, using his favourite insect Rhodnius prolixus Stål, 1859 (Exopterygota: Heteroptera: Reduviidae). Among endopterygote insects, the ground stone of insect hormone action was laid down in 1938 by Jacques J. Bounhiol, who investigated larvae and pupae of the commercial silkworm, Bombyx mori (Linnaeus, 1758) (Lepidoptera: Bombycidae). Perhaps the most important theoretical analysis of insect hormones was made by C. M. Williams, after 1947. He performed excellent surgical experiments based on induction of development in diapausing pupae by transplantations of the active brains from developing pupae, using the giant American Cecropia silkworm, H. cecropia (Lepidoptera: Saturniidae). In 1952, Williams proposed the first consolidated theory of insect hormone action (review by Williams 1952). According to the indicated hormonal concept, which is generally known as the brain-prothoracic gland (PG) theory of Williams, the developmental cycles are stimulated by the moulting hormone (growth and differentiation hormone), produced by the PG in response to the hormone released from the brain. The possible involvement of PG in developmental regulations came from the previous work of Soichi Fukuda (1944) in silkworm larvae. However, the attempts of Williams to induce development of diapausing pupae by implantations of PG alone failed. Later, Williams (1987) honestly unfounded his brain-PG theory after finding a large depot of ecdysteroid in the pupal intestine of Manduca, with the disintegrated PG.

In 1951, Hans Piepho proposed a simplified model of insect hormone action. He transplanted small pieces of larval epidermis into pupae and, conversely, pieces of pupal epidermis into the larvae of the wax moth, Galleria mellonella (Linnaeus, 1758) (Lepidoptera: Pyralidae). The implants made cystlike regenerates in the course of the moulting cycles of the host. The cuticle was deposited on the inner side of the implants. Observations on the fate of the implanted epidermis led Piepho to conclude that the polymorphic larval, pupal and adult structures were determined simply by the respectively high, medium or zero concentrations of $\mathrm{JH}$ in the haemolymph. According to this theory, for example, cells of the pupal epidermal implants developed backwards into the larval patterns under the high JH concentration in the young larval instars. The theory of Piepho was very attractive, but practically unaccountable. The results have never been repeated and verified. Unfortunately, the theory received large credibility after being approved by the authority of Sir Vincent B. Wigglesworth (1954). After 1959, endocrinologists Howard A. Schneiderman and Lawrence I Gilbert created and advertised a combination of the brain hormone-PG theory of Williams (1952) and the large-medium-zero JH theory of Piepho (1951). Their model of insect hormone action, which can be observed in Figure 1, became the widely disseminated theoretical model of insect hormone action (Schneiderman and Gilbert 1965; Novak 1966; Sláma 2013, 2015; Sláma et al. 1974). 


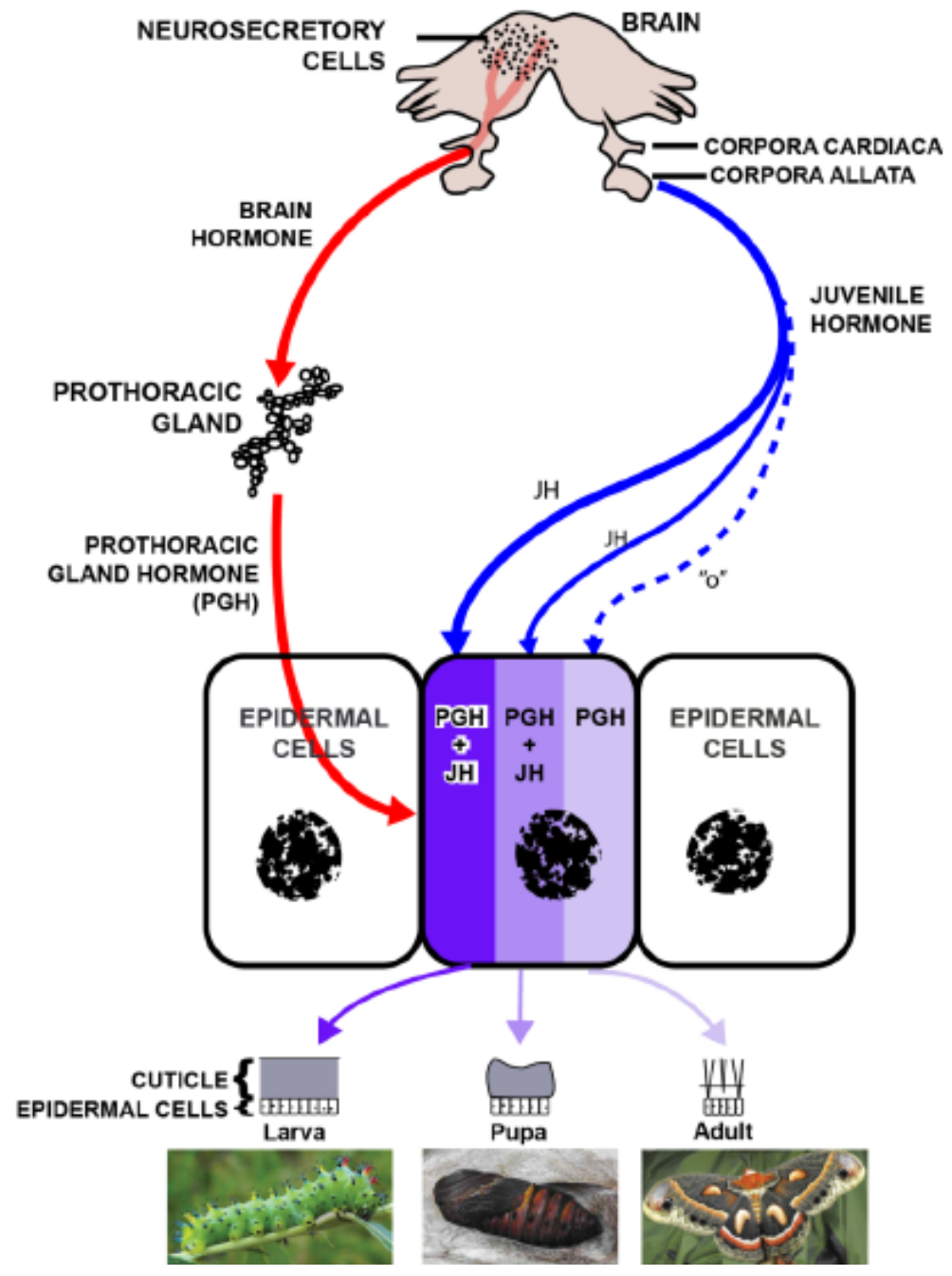

Figure 1 . The widely accepted and long time used model of insect hormone action (modified by Sláma 2013). The essential axioms are: 1. The developmental cycles are stimulated by a moulting hormone released from the prothoracic glands in response to a hormone released from the brain (Williams 1948, 1952; unfounded by Williams 1987); 2. Larval, pupal and adult epidermal structures are determined by the respectively large, medium or zero concentrations of juvenile hormone (Piepho 1951; Wigglesworth 1954, 1957; Schneiderman and Gilbert 1957, 1959, 1964; Schneiderman 1969; Gilbert 2012; Riddiford 2012; Jindra et al. 2013). Figure adapted from Schneiderman and Gilbert (1964) with permission from The American Association for the Advancement of Science [(Washington, District of Columbia, USA), Licence Number OP-00072024; issued on October 22, 2015]. 


\section{The mysterious moulting hormone}

Since the beginning of insect hormone research, endocrinologists thought that, in addition to the brain hormone, there was a special hormone for stimulation of the moulting cycles (Wigglesworth 1935 in Rhodnius; Bounhiol 1938 and Fukuda, 1944 in Bombyx; Novák 1949 in Oncopeltus (Hemiptera: Lygaeidae); and various German authors in Ephestia (Pyralidae), Galleria and other species; reviewed by Pflugfelder 1958). The existence of special moulting hormone produced by the PG in response to a prothoracicotropic hormone (PTTH) of the brain (Figure 1) became the crucial theoretical axiom for two generations of insect physiologists, biochemists, and molecular biologists (reviewed by Nijhout 1994, Nation 2002, Riddiford 2012, Gilbert 2012). Anatomically, due to their branched structure perhaps the PG of insects are most difficult insect organ to remove. Nevertheless, the gland was removed from the living insect body by several authors (Sláma 1998). In 1983, I removed the PG from several hundred penultimate and last instar larvae of Galleria (Sláma 1983). The PG-ectomised larvae performed successfully a regular sequence of the moulting cycles (larval-larval, larval-pupal and pupal-adult moults), which provided experimental evidence that these glands were used for physiological functions other than stimulation of the moults. The final evidence that the theory of Piepho did not correspond to reality was provided by Sláma (1975), who demonstrated for the first time that insect epidermal cells have only two developmental options, not three. Two decades later, it was determined by the scanning electron microscopy (SEM), that the insect epidermal cells could either repeat the extant structures under influence of JH or develop structures of the next developmental stage in the absence of $\mathrm{JH}$ (the "all or none" rule in responses of individual cells to JH; Sláma and Weyda 1997).

Recent investigations reveal that the PG of insects are exclusive targets of JH, not PTTH of the brain as it is currently anticipated (Riddiford et al. 2003, Gilbert 2012). The true physiological function of PG depends on the production of special, hitherto unknown, adipokinetic superhormone, which enables the juvenile, young larval instars to grow and survive on dry food. The hormone stimulates the augmented supply of metabolic water by the total combustion of the dietary lipid (Sláma and Lukáš 2013). This relatively prosaic hormonal role of the PG has been overshadowed by 50 years of persistent belief in the falsified hypothesis that the PG produced the moulting hormone.

\section{Ecdysone and ecdysteroids}

The polyhydroxylated derivatives of 7-dehydrocholesterol, generally known as ecdysone or ecdysteroids, were accidentally discovered by the German chemist, Peter Karlson, in the search for the insect moulting hormone. In 1965, I used to work with the late C. M. Williams at Harvard University. I remember that he received a sample of ecdysone from P. Karlson for his assays on Cecropia silkworms. The sample stimulated development of the diapausing 
pupae of Cecropia, which was considered at that time as a positive response of the moulting hormone from the PG. Based on this information and the Williams's brain-PG theory, Karlson defined the biological status of ecdysone as the moulting hormone of the PG (Karlson 1966). Ironically, this categorical definition of ecdysone survived unchanged until this time, in spite of the fact that C. M. Williams unfounded his original, brain-PG theory in 1987. The term ecdysone is also misleading. It was proposed in good faith of a chemist that the act of ecdysis, which means shedding off the old cuticle, was the same as the moult. Ecdysis is a neuromuscular physiological phenomenon triggered by special feed-back from the peripheral organs and stimulated exclusively by the myotropic peptides from the brain and the corpus cardiacum. Actually, ecdysone and ecdysteroids strongly inhibit, not stimulate, the act of insect ecdysis (Sláma 1980; for review and references see Sláma 2015b). In mammals, ecdysteroids exhibit a plethora of important pharmacological effects that are similar to the structurally related, 7- dehydrocholesterol derivatives of the sterolic D-vitamins (review by Sláma and Lafont 1995). Unfortunately, persistent belief in the arthropod moulting hormone hindered clinical investigations of the beneficial, vitamin-like effects of ecdysteroids in human medicine.

In 1966, almost immediately after disclosure of the crystallographic structure of ecdysone, phytochemists reported a widespread occurrence of ecdysone derivatives in a number of species of lower and higher plants (review by Sláma 1979, Sláma et al. 1974). Certain plants contained incredible amounts of these "insect moulting hormones". For example, just a gram of rhizomes of the fern Polypodium contained as much ecdysteroid as did 500 kilograms of silkworm pupae used for the extraction of ecdysone by Karlson. Recent phytochemists and information that can be retrieved from Internet still declare that "ecdysteroids are the arthropod moulting hormones". The chemists differentiate between the phytosterols and zoosterols (phyto- and zooecdysteroids), without being aware of the fact that the typical zoosterol, 7dehydrocholesterol, is preferentially hydroxylated by plant tissues and thus disappears from the pool of the free plant sterols. This statement is documented by a Siberian plant Leuzea carthamoides (Asteraceae) which contains 700 -fold more of the polyhydroxylated, 7-dehydrocholesterol (20-hydroxyecdysone) in comparison with the true phytosterols, ergosterol and $\beta$-sitosterol (Stránský et al. 1998).

According to Sláma (1980, 1999, 2015a, b), ecdysteroids are not insect hormones. Instead, they are homeostatic tissue factors synchronizing growth of epidermal tissues with the secretion of new cuticle. The endogenous peaks of ecdysteroid in the haemolymph are not a cause but a consequence of determined stages of the inherited morphogenetic process. Insects do not synthesize the sterol nucleus. They take it from food or symbiotic bacteria. According to a sterol utilization hypothesis (Sláma 1988), the nonfeeding metamorphosis stages of endopterygote insects reutilize the structurally bound 7-dehydrocholesterol 
derived from the outlived, disintegrated larval tissues, by its conversion into partly water soluble ecdysteroid, which is needed for the construction of membranes in the newly proliferating imaginal tissues (Figure 2).

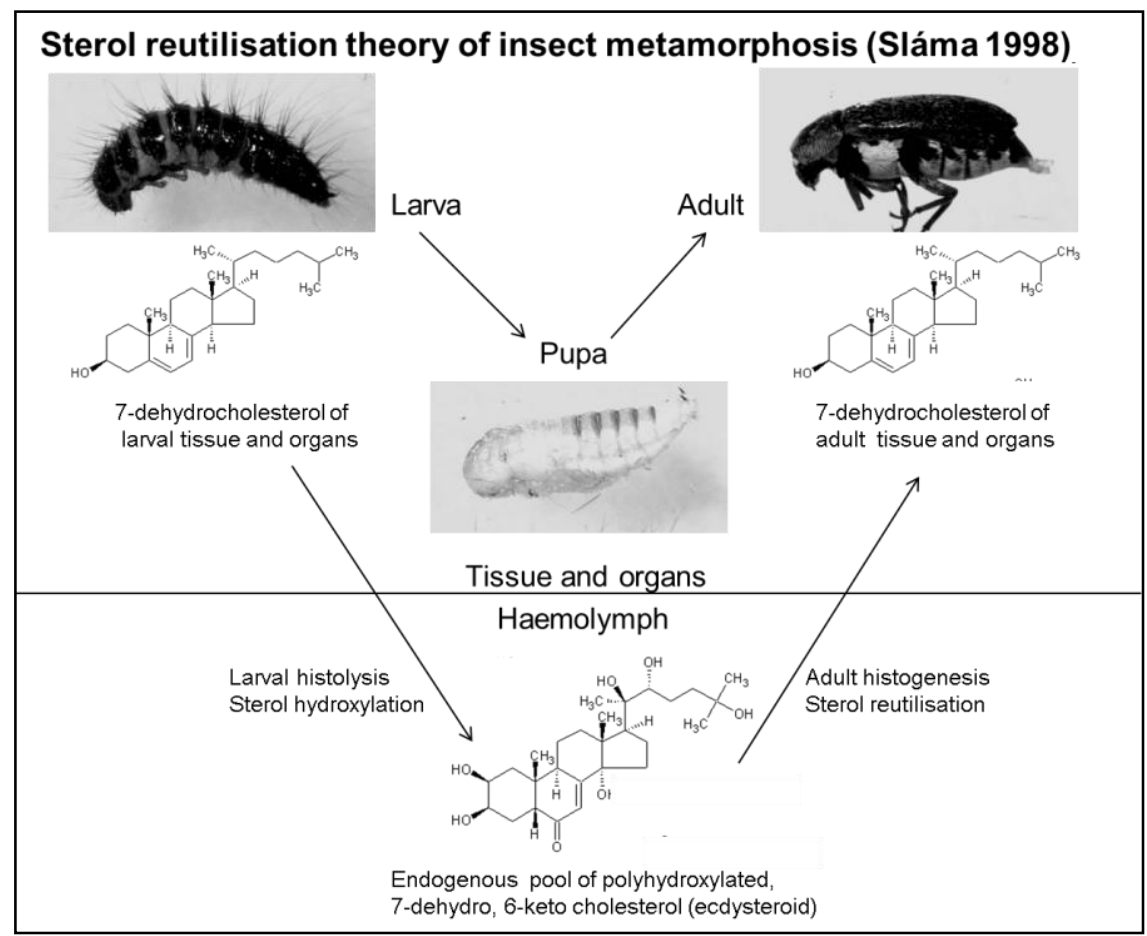

Figure 2. Schematic outline of sterol reutilisation during insect metamorphosis (modified from Sláma 1998).

Due to predominating chemical and molecular interests, the exact determination of the biological status of ecdysteroids as well as juvenoids is less important than the determination of their receptors (Jindra et al. 2015). A textbook definition of an animal hormone states that it is a chemical compound produced by specialized cells of the endocrine glands, which is released into circulatory system for the regulation of growth and metabolism in distant target tissues. Ecdysone and ecdysteroids are evidently breaching this definition, because they are liberated from multiple disintegrating peripheral tissues, not only from the deteriorated PG (Sláma 2015a). During the past five decades, the academic and industrial complex has developed circa 4,000 of mostly synthetic bioanalogues of insect JH (juvenoids, Sláma 1999). However, only one of them, the sesquiterpenoid epoxyhomofarnesoate ester, known as the JH-I, found in the male abdomens of Cecropia silkworms, was advertised as the true JH. Yet, well 
before 1965, JH-activity was encountered in a number of lipid extracts prepared from microorganisms and plants, from ordinary milk cream, human placenta, adrenal cortex of vertebrates and some, but not all, insects. Many scientific papers have described the properties and the mode of action of JH-I (Gilbert 2012). However, I never considered that epoxyhomofarnesoate ester could be the true $\mathrm{JH}$, because it was more than a million-fold less active in comparison with certain, synthetically prepared peptidic juvenoids (Sláma et al. 1974).

Recent investigations (Paroulek and Sláma 2014) provide clear experimental evidence that the isoprenoid JH-I cannot represent the true corpus allatum hormone. It constitutes, together with the isoprenoid vitamin $\mathrm{E}$, an excretory product of the exocrine, not endocrine, colleterial gland of the male Cecropia silkworm. Its function is to stabilise sperm survival within the male ejaculate. In addition, the isoprenoid JH-I does not play any other physiological role in the non-feeding, adult stage of the silkworms, which have completely inactive corpora allata. The production of JH-I in purely exocrine, not endocrine, colleterial gland evidently breaches the general definition of an animal hormone (Sláma 2015a).

\section{What are the true insect hormones?}

Provided that the low-molecular compounds, ecdysone and JH-I are not the true insect hormones, a question arises what are then the real metamorphosis hormones of insects, where they originate and what are their physiological functions? During the past 100 years, insect endocrinologists accumulated a lot of data concerning the structure and function of the central neuroendocrine system (Raabe, 1982). This system is composed of neurosecretory cells in the insect brain, the neurohaemal organ, known as corpora cardiaca, and the glandular organ, known as corpora allata (Hanstrom 1939, Scharrer and Scharrer 1944, Pflugfelder 1958, Novák 1966, Sláma et al. 1974). The central neuroendocrine system underwent specific modifications during millions of years of animal phylogenesis. The hormones of the central neuroendorine system are mostly peptides or proteins. In contrast to the low molecular regulatory substances, their action needs to be prolonged over many minutes, hours or even days. This is achieved by extremely high biological activity of the proteinic hormones $\left(10^{-9} \mathrm{M}\right.$ conc.), which is practically out of the reach of the inactivating aminopeptidase enzymes (First order kinetic close to $10^{-6} \mathrm{M}$ ). Earlier experiments based on removal or transplantation of the main endocrine centers revealed the presence of basically two categories of endocrine developmental regulations. 


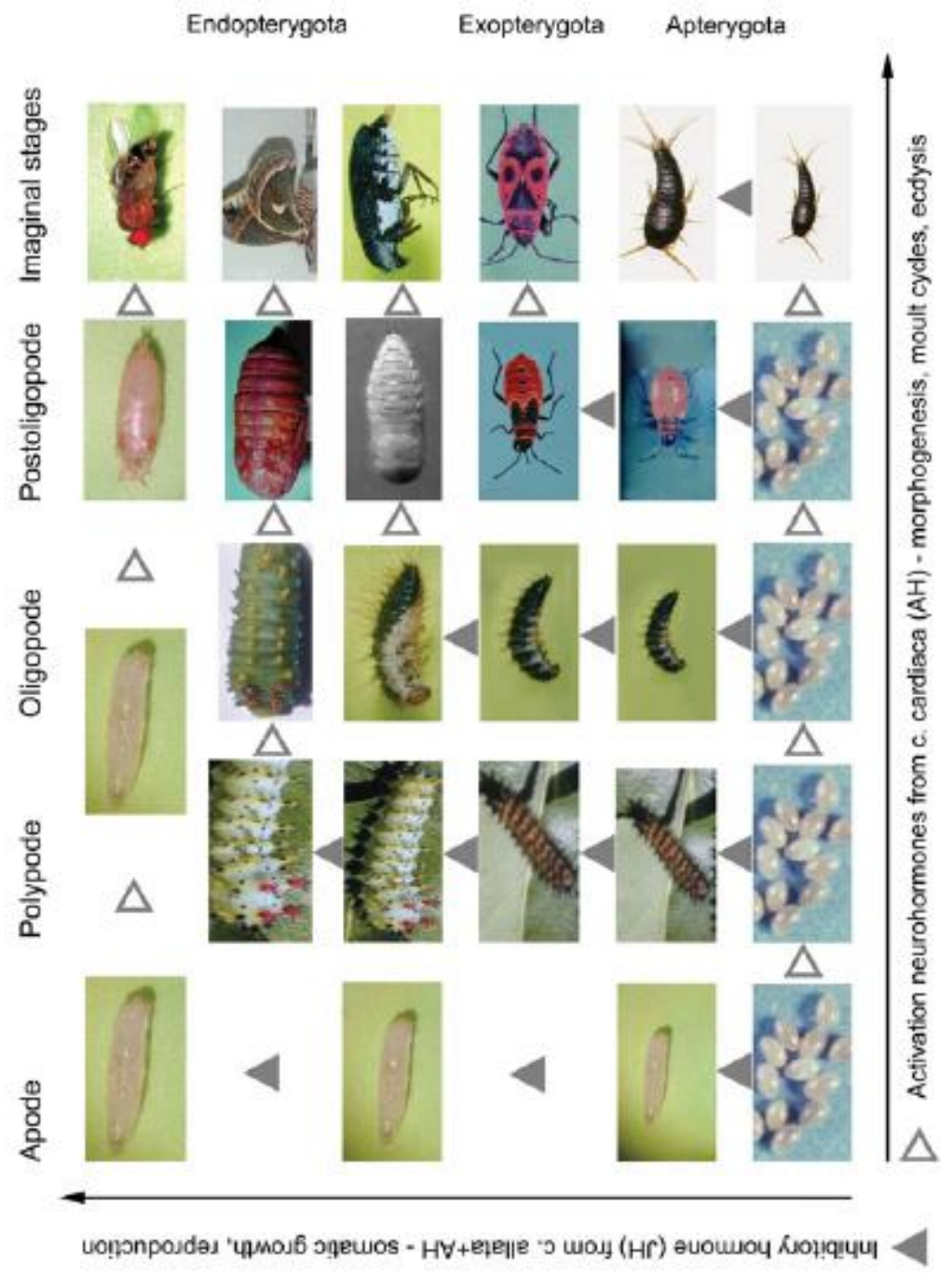

Figure 3. Schematic outline of the hormonal control of insect metamorphosis by a simple interaction of two hormones released from the central neuroendocrine system: a) Neuropeptides (AH) produced in the neurosecretory cells of the brain and released into haemolymph from the corpora cardiaca; b) The morphogenesis inhibiting hormone $(\mathrm{JH})$ secreted by the corpora allata. According to hormonal theory of Novák-Sláma, AH stimulates the cycles of cell proliferation (moult cycles) between the genetically predetermined start-stop positions. The presence of $\mathrm{JH}$ (upward direction) temporarily "freezes" the attained ontogenetic stage ("the status quo" effect) by the induction of isometric cycles of larval somatic growth. (From Sláma 1995, 2013, with modifications). Reproduced with permission from Brill, Leiden, The Netherlands (L. Westbrook to Santiago-Blay, personal communication October 22, 2015). 
The first category included the peptidic neurohormones of the neurosecretory cells, which were known in the old times as the Gomori-positive materials. The active material was produced in neurosecretory cells, transported along their axons into the neurohaemal glands, corpora cardiaca, from where it was released into the haemolymph. The complex of hormones produced by the central or lateral groups of the neurosecretory cells (Raabe 1982) was named by pioneers of insect endocrinology as the activation hormone (AH) (Novák 1966).

Today, we know more than a dozen of immunoreactive neuropeptides synthesized in the neurosecretory cells of the brain and ganglia of the ventral nerve cord (Nässel 2002). Unfortunately, it is not known whether some of the known neuropeptides are the brain hormone of Kopeć and Williams. The neuropeptides $(\mathrm{AH})$ of the brain stimulate growth, cell proliferation, and coordination of moulting cycles with the favourable environmental conditions (long day, increased temperature, availability of food).

The second category of insect hormones is the metamorphosis-inhibiting juvenile hormone $(\mathrm{JH})$ secreted by the corpora allata. This hormone never acts alone. Instead, it always only modifies the action of the AH by installing stationary somatic growth in the feeding larvae or ovarian growth in the adults. The starved larvae or starved females do not initiate the cycles of growth, there is no $\mathrm{AH}$, no growth so that the functions of $\mathrm{JH}$ alone cannot be executed. A unique feature of $\mathrm{JH}$ among the animal hormones is the occurrence of several thousands of the human made, synthetic bioanalogues (Henrick 1995; Sláma 1985, 1999, 2013; Sláma et al. 1974), which mimic exactly all effects of the hormone produced in insect corpora allata.

Recent topics of insect hormone research have been modernized and transferred from physiology into biochemistry and molecular biology. However, the old physiological problems remained unresolved. The new generations of scientists tend not to test 50-years-old hypotheses and their methods are different. There are new theories which propose that, instead of being regulated by the centrally produced hormones $(\mathrm{AH}, \mathrm{JH})$, insect development is regulated from the periphery, by enzymes (e.g. esterase) or genes (Met, broad spectrum genes) of the subordinated, peripheral target tissues (Devillers 2013, Jindra et al. 2013, 2015). The central neuroendocrine system ( $\mathrm{AH}, \mathrm{JH})$ acquired during evolution the dominant, epigenetic control over the genes displaced on chromosomes of their peripheral tissue targets. In other words, the centrally produced hormones evolved the ability to tell the peripheral genes when comes the right time for execution of their inherited developmental instructions coded on the genome. The hormonal instructions are synchronised with the favourable environmental conditions (Sláma 2015a). A simplified developmental scheme illustrating regulation of insect development and metamorphosis by interplay of the two centrally produced hormones, $\mathrm{AH}$ and $\mathrm{JH}$, is illustrated in Figure 3. 


\section{Evolutionary pathways in animal endocrinology}

Anatomical and morphological structures of the neuroendocrine system show distinctive evolutionary changes during the animal phylogeny. There are simple neurosecretory neurons occurring already around prostomium of coelenterates (Cnidaria). There are also distinctive secretory neurons in the cephalic ganglia of flatworms (Platyhelminthes) and segmented worms (Annelida), and the associated endocrine glands in cephalopods (Mollusca) and arthropods (Sláma 1982). The principal hormonal systems of invertebrates and vertebrates show striking structural and functional analogies.

According to Devillers (2013), 37\% genes found in the genome of Drosophila have their counterparts in the human genome. Moreover, the primordial formation and function of insect heart are orchestrated by similar sets of the genes that are used for the human heart. The contractions of the myocardium are both present in the human and insect hearts based on absolutely similar, involuntary, purely myogenic principles (Sláma 2012). During the 1940s, physicians studying the action of human hormones noticed the striking similarities between anatomical structures of the neuroendocrine systems of insects and humans (Hanstrom 1939, Scharrer and Scharrer 1944). A schematic outline of these similarities is presented in Figure 4. It shows apparent homology between anatomical and morphological structures of the neurosecretory cells located in the human hypothalamus and in the central and lateral pars of insect brains. There are further structural and functional homologies between the human neurohypophysis and the corpora cardiaca of insects and also between the glandular adenohypophysis and the corpora allata of insects.

The scheme in Figure 4 contains one serious disproportion related to chemical structure of the corpus allatum hormone. Namely, the glandular adenohypophysis, which is apparently homologous with the c. allatum, produces exclusively proteinaceous hormones while the corpus allatum of insects is thought to synthesize a low-molecular, sesquiterpenoid JH-I. Theoretically, a possible evolutionary switchover between the proteinic and isoprenoid hormone of the identical biological function can hardly be imagined. It is highly demanding, therefore, to take into account the previous conclusions of Novák (1966) and Sláma et al. (1974) about possible proteinic nature of the corpus allatum hormone (Sláma 2015a). 


\section{INSECTS}

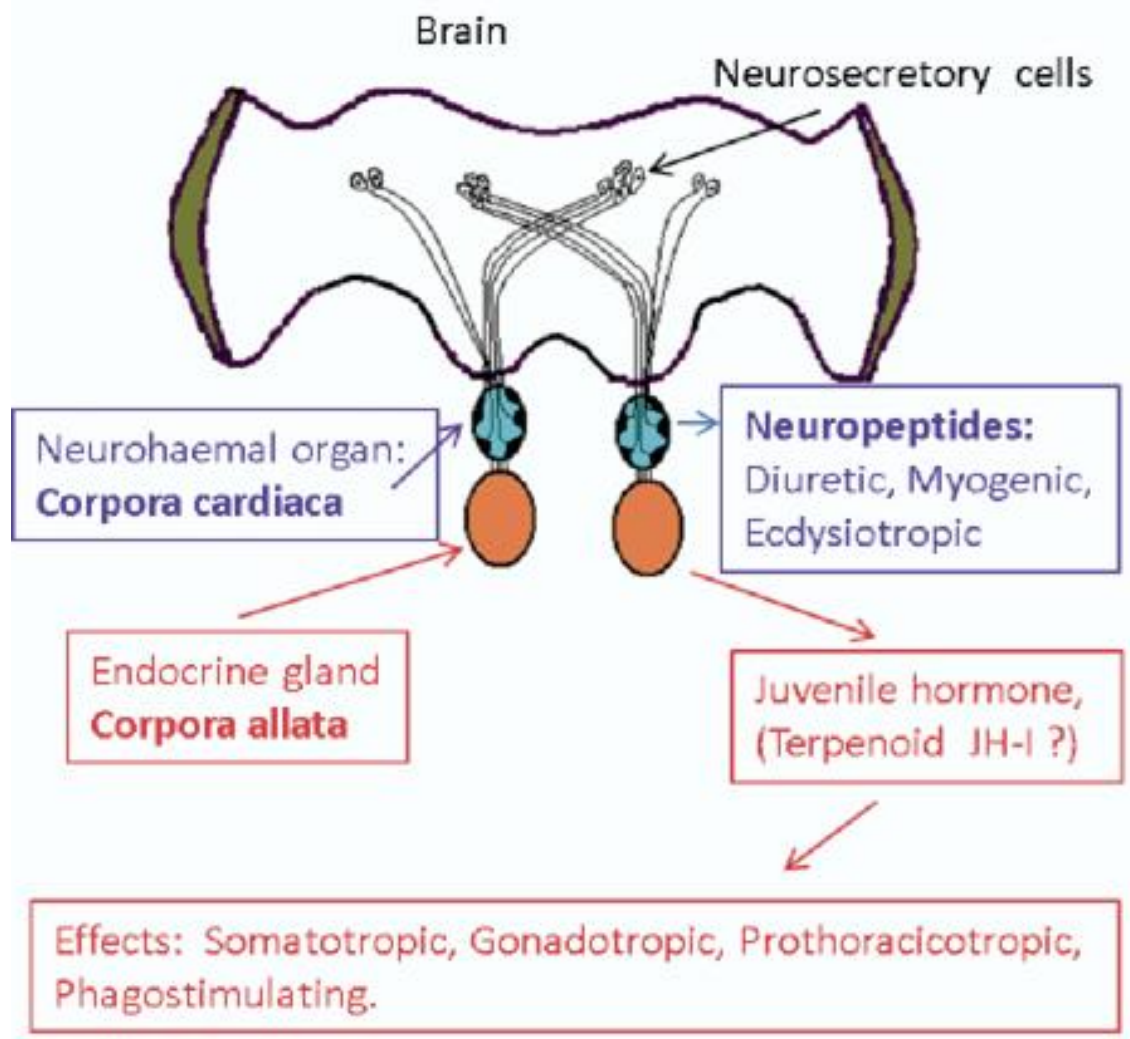

Figure 4. Evolutionary links between the neuroendocrine systems of insects and humans. The homologous endocrine structures are: a) neurosecretory cells (NSC) of insect brain and the NSC of mammalian hypothalamus; b) neurohaemal ogans represented by corpora 


\section{HUMANS}

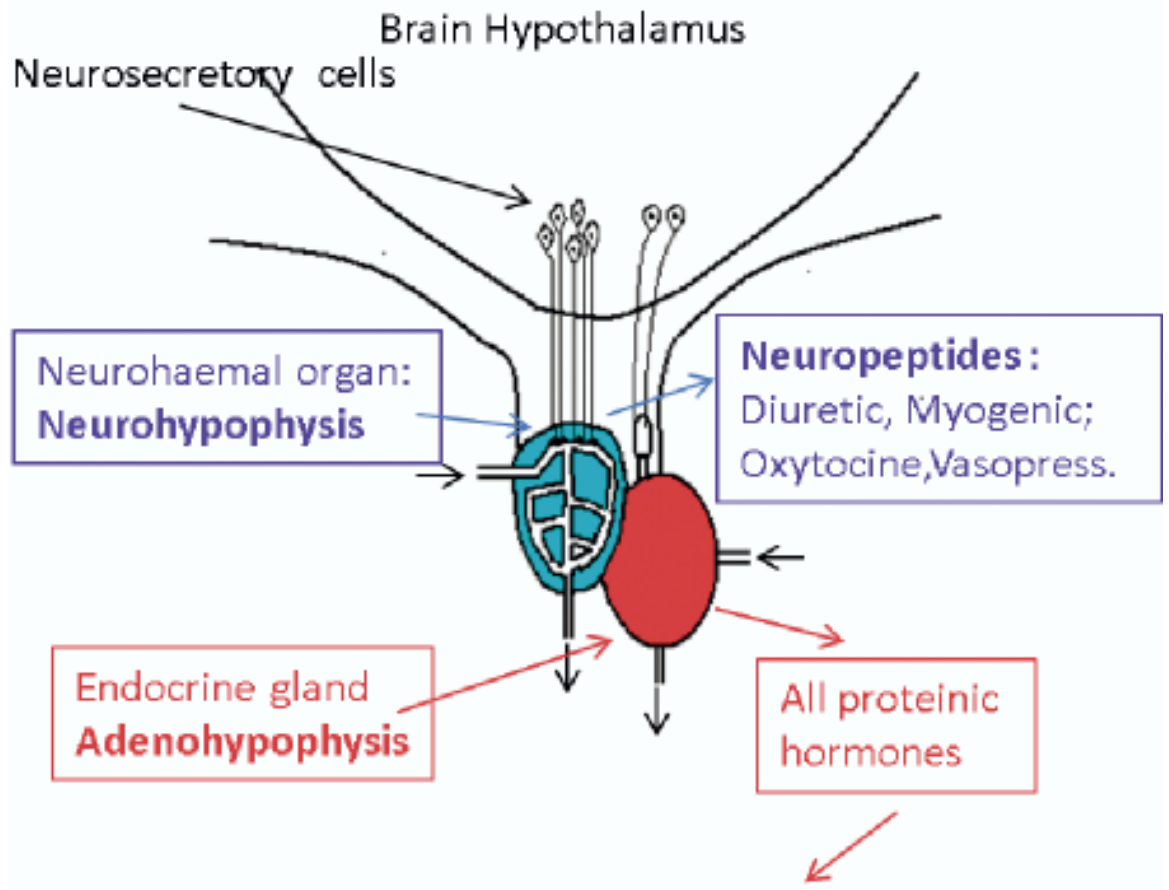

Effects: Somatotropic, Gonadotropic, Adrenocorticotropic, Thyreotropic, Luteinisation, Prolactin.

cardiaca in insects and neurohypophysis of the mammals, and; c) endorine glands represented by corpora allata of insects and adenohypophysis of the mammals (adapted from Sláma 2015a). 
Modern biological sciences that use insects as study organisms, such as molecular biology, genetics of Drosophila, biochemistry and peptide chemistry, made a great leap forward during the past decades, leaving insect morphology and physiology of insect development far behind. The scope of insect science has been moved into new, previously unknown fields. There are many recent papers on insect juvenile hormone, with 4000 of its bioanalogues, although I believe that we still do not know chemical structure of the true corpus allatum hormone. I wonder how we can arrive to meaningful results, if we still follow pathways that I consider misleading. The above described, physiological interpretations of insect hormone action may hopefully help to find better experimental approaches.

\section{Contrasting perspectives on insect endocrinology: a summary}

According to Sláma (2013), there are two explanations for the action of insect hormones. The commonly recognized theory of Gilbert and Riddiford, which proposes that insect development is stimulated by a moulting hormone released from the prothoracic glands (PG) in response to the prothoracicotropic hormone (PTTH) of the brain. The larval, pupal or adult epidermal structures of insects are formed in response to the respectively high, medium or zero concentrations of JH (Figure 1). Alternatively, the theory of Novák and Sláma proposes that the PG do not secrete a moulting hormone. Instead, the PG are the exclusive target of JH, not PTTH, functioning and releasing their hormone only during the feeding period of the young larval stages. Novák and Sláma consider the concentration of $\mathrm{JH}$ to be unimportant, as long as there is, at least, a minimum physiologically effective JH concentration. The hormones produced by the central neuroendocrine system play a superimposed, or epigenetic, role on subordinated genes present on the chromosomes of the peripheral tissue or cells. In contrast, the Gilbert-Riddiford interpretation of $\mathrm{JH}$ action, which can be found in most recent publications, proposes that genes of the peripheral somatic cells are responsible for the action of the centrally produced hormones (Riddiford 2012, Jindra et al. 2013, 2014, reviewed by Gilbert 2012).

A recent monograph on insect JH (Devillers 2013a, b) infers that juvenile hormones are all isoprenoids (Jindra et al. 2013). Moreover, the most recent report on $\mathrm{JH}$ signaling states that the mechanisms underlying the action of $\mathrm{JH}$ were until recently unknown (Jindra 2014, Jindra et al. 2015). A breakthrough has been the presented demonstration that the bHLH-PAS protein Met is an intracellular receptor for $\mathrm{JH}$. Binding of $\mathrm{JH}$ to Met triggers dimerization of Met with its partner protein Tai, and the resulting complex induces transcription of target genes. This simple, JH-activated pathway is responsible for maintaining the juvenile status during the early postembryonic development when larvae/nymphs lack competence to metamorphose (Jindra et al. 2015).

In the light of the above described, straight-forward molecular pathways, the 50-year-old sophistications about interactions between PTTH, PG, 
ecdysteroids, JH-I, peripheral enzymes and genes could be easily reconciled. In contrast to this, however, the most recent papers of Sláma $(2013,2015 a)$ deny the regulatory role of the peripheral enzymes and genes in the control of insect hormone action which is, however, a common interpretation of hormonal action found in the most recent publications (Smith and Rybczynski 2012; Hui et al. 2013; Yamanaka et al. 2013; Smýkal et al. 2014a, b). In addition to the resolved role of JH signaling (Jindra et al. 2015) and the contradictory, epigenetic role of insect hormones (Sláma 2013, 2015a), there are also other interpretations of the hormonal action, based on biochemical, not physiological, considerations (Schooley et al. 2012; De Loof et al. 2013, 2014).

\section{Ackowledgements}

I am indebted to all anonymous reviewers who understand alternative interpretations of insect hormone action.

\section{Literature Cited}

Generally, the amount of literature data pertaining to the hormonal theory of GilbertRiddiford is enormous (reviewed by Gilbert 2012). Since the alternative, endocrinological interpretations of Novák-Sláma are almost unknown, I am presenting here a more extensive list of the related references.

De Loof, A., B. Boerjan, U. R. Ernst, and L. Schoofs. 2013. The mode of action of juvenile hormone and ecdysone: Towards an epi-endocrinological paradigm? General and Comparative Endocrinology 188:35-45. http://dx.doi.org/10.1016/j.ygcen.2013.02.004

De Loof, A., W. De Haes, T. Janssen, and L. Schoofs. 2014. The essence of insect metamorphosis and aging: Electrical rewiring of cells driven by the principles of juvenile hormone-dependent $\mathrm{Ca}^{2+}$-homeostasis. General and Comparative Endocrinology 199:70-85. http://dx.doi.org/10.1016/j.ygcen.2014.01.009

Devillers, J. 2013a. Juvenile hormones and juvenoids. Modeling biological effects and environmental fate. CRC Press, Taylor and Francis Group. Boca Raton, Florida, USA. 387 pp. ttp://dx.doi.org/10.1201/b14899

Devillers, J. 2013b. Juvenile hormones and juvenoids: A historical survey. In, Devillers J. (Editor): Juvenile Hormones and Juvenoids. Modeling Biologial Effects and Environmental Fate. CRC Press. Boca Raton, Florida, USA, pp. 1-14. http://dx.doi.org/10.1201/b14899-2

Fukuda, S., 1944. The hormonal mechanism of larval moulting and metamorphosis in the silkworm. Journal of Faculty of Science, Tokyo University. Section IV 6:477-532.

Gilbert, L. I. 2012. Insect Endocrinology. Elsevier. Amsterdam, The Netherlands. 577 pp.

Hanström, B. 1939: Hormones in Invertebrates. Oxford University Press. London, England; Edinburgh, Scotland, UK. 198 pp.

Henrick, C. A. 1995. Juvenoids. pp. 147-213. In, Godfrey C. R. A. (Editor). Agrochemicals from natural products. Marcel Dekker. New York, NY, USA. 418 pp.

Hui, J. H. L., W. G. Bendena, and S. S. Tobe. 2013. Future perspectives for research on the biosynthesis of juvenile hormones and related sesquiterpenoids in Arthropod endocrinologty and ecotoxicology. In, Devillers, J. (Editor) Juvenile Hormones and Juvenoids. Modeling Biologial Effects and Environmental Fate. CRC Press. Boca Raton, Florida, USA, pp. 15-30. http://dx.doi.org/10.1201/b14899-3 
Jindra, M. 2014. Met/Gce is a bona fide JH receptor. Plenary Lecture. In, Proceedingsv of 10th International Conference on Juvenile Hormones. National Institute of Agrobiological Sciences. Tsukuba, Japan. p. 5.

Jindra, M., S. R. Palli, and L. M. Riddiford. 2013. The juvenile hormone signaling pathway in insect development. Annual Review of Entomology 58, 181-204. http://dx.doi.org/10.1146/annurev-ento-120811-153700

Jindra, M., X. Bellés, and T. Shinoda. 2015. Molecular basis of juvenile hormone signaling. Current Opinion in Insect Science 11:39-46. http://dx.doi.org/10.1016/j.cois.2015.08.004

Kopeč, S. 1922. Studies on the necessity of the brain for the inception of insect metamorphosis. Biological Bulletin 42:223-242. http://dx.doi.org/10.2307/1536759

Nation, J. L. 2002. Insect Physiology and Biochemistry. CRC Press. Boca Raton, Florida, USA. 485 pp.

Nässel D. R. 2002. Neuropepti des in the nervous system of Drosophila and other insects: multiple roles as neuromodulators and neurohormones. Progress in Neurobiology 68:184. http://dx.doi.org/10.1016/S0301-0082(02)00057-6

Nijhout, H. F. 1994. Insect Hormones. Princeton University Press. Princeton, New Jersey, USA. 267 pp.

Novak, V. J. A. 1966. Insect Hormones. Methuen. London, UK. 478 pp.

Paroulek, M. and K. Sláma. 2014. Production of the sesquiterpenoid, Juvenile Hormone-1 (JHI), and of Vitamin E in the accessory sexual (colleterial) glands of adult male moths, Hyalophora cecropia (Linnaeus, 1758) (Lepidoptera: Saturniidae). Life: The Excitement of Biology 2(1):102-124. http://dx.doi.org/10.9784/LEB2(2)Paroulek.01

Pflugfelder O. 1958. Entwicklungsphysiologie der Insekten. Akademische Verlagsgesellschaft Geest und Portig. Leipzig, Germany. 490 pp.

Piepho, H. 1951. Über die Lenkung der Insektenmetamorphose durch Hormone. Verhandlungen Deutschen Zoologisher Gesellschaft (Wilhelmshaven) 1951:62-75.

Raabe, M. 1982. Insect Neurohormones. Plenum Press. New York, NY, USA. 352 pp. http://dx.doi.org/10.1007/978-1-4684-4013-3

Riddiford, L. M. 2012. How does juvenile hormone control metamorphosis and reproduction? General and Comparative Endocrinology 179:477-484. http://dx.doi.org/10.1016/j.ygcen.2012.06.001

Riddiford, L. M., K. Hiruma, X. Zhou and Ch. A. Nelson. 2003. Insights into the molecular basis of the hormonal control of molting and metamorphosis from Manduca sexta and Drosophila melanogaster. Insect Biochemistry and Molecular Biology 33:1327-1336. http://dx.doi.org/10.1016/j.ibmb.2003.06.001

Röller, H. and J. S. Bjerke. 1965. Purification and isolation of juvenile hormone and its action in Lepidopteran larvae. Life Sciences 4:1617-1624. http://dx.doi.org/10.1016/00243205(65)90141-4

Röller, H., J. S. Bjerke, L. M. Holthaus, D. W. Norgard, and W. H. McShan. 1969. Isolation and biological properties of the juvenile hormone. Journal of Insect Physiology 15:379389. http://dx.doi.org/10.1016/0022-1910(69)90285-6

Scharrer, B. and E. Scharrer. 1944. Neurosecretion. VI. A comparison between the intercerebralis-cardiacum-allatum system of insects and the hypothalamo-hypophysial system of vertebrates. Biological Bulletin 87:242-251. http://dx.doi.org/10.2307/1537959

Schneiderman, H. A. 1969. Control systems in insect development. pp. 186-208. In, Devons, S. (Editor). Biology and the Physical Sciences. Columbia University Press. New York, NY, USA. 379 pp.

Schneiderman, H. A. and L. I. Gilbert, 1957. The distribution and chemical properties of the juvenile hormones of insects. The Anatomical Record 128:618.

Schneiderman, H. A. and L. I. Gilbert. 1959. The chemistry and physiology of insect growth hormones. pp. 157- 187 In, Rudnick, D. (Editor). Cell, Organism and Milieu. 17 ${ }^{\text {th }}$ 
Symposium. Society for the Study of Development and Growth (U.S.). Ronald Press Company. New York, NY, USA. 326 pp.

Schneiderman, H. A. and L. I. Gilbert. 1964.Control of growth and development in insects. Science 143(3604):325-333. http://dx.doi.org/10.1126/science.143.3604.325

Schooley, D. A., M. Horodyski, and G. M. Coast. 2012. Hormones controlling homeostasis in insects. In, Gilbert L. I. (Editor). Insect Endocrinology. Elsevier. Amsterdam, The Netherlands, p. 366-429. http://dx.doi.org/10.1016/B978-0-12-384749-2.10009-3

Schmialek, P. 1961. Die Identifizierung zweier in Tenebriokot und in Hefe vorkommender Substanzen mit Juvenilhormonwirkung. Zeitschrift für Naturforschung 16b:461-464.

Schmialek, P. 1963a. Über die Bildung von Juvenilhormonen in Wildseidenspinnern. Zeitschrift für Naturforschung 18b:462-465.

Sláma, K. 1975. Some old concepts and new findings on hormonal control of insect morphogenesis. Journal of Insect Physiology 21:921-955. http://dx.doi.org/10.1016/0022-1910(75)90019-0

Sláma, K. 1979. Insect hormones and antihormones in plants. In, Rosenthal G.A. and D. H. Jansen (Editors). Herbivores: Their Interaction with Secondary Plant Metabolites. Academic Press. New York, NY, USA and London, England, UK, pp. 683-700.

Sláma, K. 1980. Homeostatic function of ecdysteroids in ecdysis and ovi position. Acta Entomologica Bohemoslovaca 77:145-168.

Sláma, K. 1982. Hormonal control of morphogenesis in Invertebrates, evolutionary aspects. Journal of General Biology (Moscow) 43:805-822.

Sláma, K. 1983. Illusive functions of the prothoracic gland in Galleria. Acta Entomologica Bohemoslovaca 80:160-176.

Sláma, K. 1998. The prothoracic gland revisited. Annals of the Entomological Society of America 91:168-174. http://dx.doi.org/10.1093/aesa/91.2.168

Sláma, K. 1995. The present status of the mode of action of insect juvenile hormone. Netherlands Journal of Zoology 45:71-78. http://dx.doi.org/10.1163/156854295X00618

Sláma, K. 1999. The history and current status of juvenoids. In Robinson, W. M., F. Rettich, and G. W. Rambo (Editors). Proceedings of 3rd International Conference on Urban Pests. July 19-22, 1999. Hronov, Czech Republic, p. 9-25.

Sláma, K. 2012. A new look at the comparative physiology of insect and human hearts. $\begin{array}{lllll}\text { Journal of Insect } & \text { Physiology } & 58 & \text { (2012):1072-1081. }\end{array}$ http://dx.doi.org/10.1016/j.jinsphys.2012.04.014

Sláma, K. 2013. Insect hormones: more than 50-years after the discovery of insect juvenile hormone analogues (JHA, juvenoids). Terrestrial Arthropod Reviews 6(4):257-333. http://dx.doi.org/10.1163/18749836-06041073

Sláma, K. 2015a. A new look at the nature of insect juvenile hormone with particular reference to studies carried out in the Czech Republic. European Journal of Entomology 112 (4). http://dx.doi.org/10.14411/eje.2015.073. Final pagination on printed version not available at the time this article went to press.

Sláma, K. 2015b. Comprehensive physiology of ecdysogens - the metabolically activated porphyrin-ecdysteroid complexes in insects. Comparative Biochemistry and Physiology $C$ (accepted).

Sláma, K. and R. Lafont. 1995. Insect hormones - ecdysteroids: their presence and actions in vertebrates. European Journal of Entomology 92:355-377.

Sláma, K. and J. Lukáš. 2013. Role of juvenile hormone in the hypermetabolic production of water revealed by the $\mathrm{O}_{2}$ consumption and thermovision images of larvae of insects fed a diet of dry food. European Journal of Entomology 110:221-230. http://dx.doi.org/10.14411/eje.2013.032 
Sláma, K. and F. Weyda. 1997. The all-or-none rule in morphogenetic action of juvenile hormone on insect epidermal cells. Proceedings of the Royal Society of London B 264:1463-1470. http://dx.doi.org/10.1098/rspb.1997.0203

Sláma, K., M. Romaňuk, and F. Šorm. 1974. Insect Hormones and Bioanalogues. Springer. Wien, Austria. New York, NY, USA. 477 pp. http://dx.doi.org/10.1007/978-3-70918331-1

Smith, W. and R. Rybczynski, 2012. Prothoracicotropic hormone. pp. 1-62. In Gilbert L. I. (Editor). Insect Endocrinology. Elsevier, Amsterdam, The Netherlands, pp. 1-62. http://dx.doi.org/10.1016/B978-0-12-384749-2.10001-9

Smýkal, V., T. Daimon, T. Kuyakawa, K. Takashi, T. Shinoda and M. Jindra, 2014a. Importance of juvenile hormone signaling arises with competence of insect larvae to metamorphose. Developmental Biology 390:221-230. http://dx.doi.org/10.1016/j.ydbio.2014.03.006

Smýkal, V., A. Bajgar, J. Provazník, S. Fexová, H. Bư̌ičová, K. Takaki, M. Hodková, M. Jindra and D. Doležel, 2014b. Juvenile hormoe signaling during reproduction and development of the linden bug Pyrrhocoris apterus. - Insect Biochemistry and Molecular Biology 45:69-76. http://dx.doi.org/10.1016/j.ibmb.2013.12.003

Stránský, K., V. Němec, and K. Sláma, 1998. Lipid composition of the seeds of an ecdysteroid-containing plant, Leuzea cathamoides (Willd.) DC (Asteraceae). Russian Journal of Plant Physiology 45:390-396.

Wigglesworth, V. B. 1936. The function of the corpus allatum in the growth and reproduction of Rhodnius prolixus. Quarterly Journal of Microscopic Science 79:91-119.

Wigglesworth, V. B. 1940. The determination of characters at metamorphosis in Rhodnius prolixus. Journal of Experimental Biology 17:201-222.

Wigglewworth, V. B. 1954. The Physiology of Insect Metamorphosis. Cambridge University Press. Cambridge, England, UK. 152 pp.

Wigglesworth 1957. The action of growth hormones in insects. Symposia of Society for Experimental Biology 11:204-227.

Williams, C. M. 1947. Physiology of insect diapause II. Interaction between the pupal brain and prothoracic glands in the metamorphosis of the giant silkworm, Platysamia cecropia. Biological Bulletin 93:89-98. http://dx.doi.org/10.2307/1538279

Williams, C. M. 1952. Physiology of insect diapause. IV. The brain and prothoracic glands as an endocrine system in the Cecropia silkworm. Biological Bulletin 103:120-138. http://dx.doi.org/10.2307/1538411

Williams, C. M. 1956. The juvenile hormone of insects. Nature 178:212-213. http://dx.doi.org/10.1038/178212b0

Williams, C. M. 1987. Midgut of lepidopteran pupae is a major depot of sequestered, mobilizable ecdysteroids. Memórias do Institute Oswaldo Cruz 82:47-49. http://dx.doi.org/10.1590/S0074-02761987000700010

Yamanaka, N., K. F. Rewitz, and M. B. O’Connor, 2013. Ecdysone control of developmental transitions: lessons from Drosophila research. Annual Reviews of Entomology 58:497516. http://dx.doi.org/10.1146/annurev-ento-120811-153608 